\title{
Design and Construction of Egusi (Igbo, Coutry and Pumpkin) Cracking Machine
}

\author{
Yakum Reneta Nafu \\ Department of Mechanical Engineering, HigherTechnical Teacher Training College \\ The University of Bamenda Cameroon \\ Email: yakumnafu [AT] gmail.com
}

\begin{abstract}
The time consuming, boring, and strenuous process of cracking egusi seeds manually has provoked researchers and machine fabricators locally construct motorized systems to replace manual efforts. In a bid to improve on the cracking performance of their system, a critical analysis was carried out and fine out that the machine fabricated locally was done only for Igbo egussi in Nigeria. Amongst others, it was found out that the current systems were still manually processed like Contry egusi and Pumpkin egusi in Cameroon. This machine is designed and constructs to be used across age gender for domestic, commercial and industrial for cracking egusi seed to have the egusi kernel. Proper design considerations were then put in place, and an improved and more reliable version constructed, taking into consideration three different categories of egusi locally grown in Cameroon. The improved version gave far higher efficiencies of $80.5 \%$, $85.5 \%$, and $89.5 \%$ at crack at the best (experimented and prescribed) water-to-seed ratio.
\end{abstract}

Keywords--- Egusi cracking machine, Igbo egusi, Contry egusi, pumpkin egusi

\section{INTRODUCTION}

Melon plant is one of the most popular vegetable crops grown in Africa. It's a tendril herbaceous annual growing crop. The seeds belong to the cucumber family, and are popularly called "Egusi", a name widely used throughout West Africa [1]. Grinded Egusi seeds are a common component of daily meals, used in the preparation of local soups, stews and puddings. Analysis made on Egusi seeds [2] indicated that Egusi seeds consist of 50\% oil, 37.4\% protein, $2.6 \%$ fibre, 3.6\% ash, and $6.4 \%$ moisture by weight. The shells can be used as a potential poultry feed ingredient [3]. Nwosu, (1988) [4] indicate that Egusi pods have an almost spheroidal external with an ellipsoidal seed cavity, Further, the elastimodulus increases significantly from the inner part to the rind [5]. Egusi seed oil contains a high level of unsaturated fatty acids which has a wide use both for domestic and industrial purposes. Domestic use of egusi oil include soup cooking, frying etc., while industrially it can be used for production of soap, pomade, metal polish, lubricant adhesive, candles, feed for cattle such as poultry, pigs, sheep and goats. The melon plant is also an important component of the traditional cropping system usually inter-planted with such staple crops as cassava, maize, sorghum etc [6] Recent statistics show that over 4,225 metric tons of Egusi were produced by the South West Region in Cameroon alone in from January - June. The largest amount came from Manyu Division (3,752 tons) and the rest of the 6month's production is unevenly divided amongst the other divisions of the South West Region, with Kupemuaneguba Division producing the least, 20 tons (Regional Office of Agricultural Statistics and Survey Buea, 2013. Cognizant of the fact that Egusi production does not only end in the South West Region in Cameroon but also being produced in heavy quantities in a majority of the other 10 Regions of Cameroon, one therefore remains convinced that Cameroon has the potential of processing these seeds industrially. Processing of the Melon fruit include; fermentation, coring, washing, drying, cracking, and seed oil extraction. Traditional methods of cracking egusi seeds is slow, time consuming, tedious, inefficient, and involves drudgery, thus limiting the availability of the finished product in the market. This has given concern to scientists and researchers in recent past, particularly since women are the major processors of the melon plant especially at the cracking stage [7] The drudgery associated with manual Egusi processing before its end use influences to a greater extent its cultivation and accounts for its relatively high market price compared to other protein food sources like groundnut and soya beans. So, despite the large farm production potential that Cameroon presents, and the nutritional potential of melon seeds, there has been a hindrance ( or no interest) to the industrialization of the oil gotten from this food crop because of the challenges associated with traditional-manual process of the cracking the seeds [8]. Attempts have also been made to crack the seeds of contry egusi (that with very hard shell) and pumpkin egusi (which have with soft thick shell) with the teeth or a piece of metal, but these other manual technics also remain very unhygienic, very slow and less reliable. 
There have been works on the development and use of the egusi seed shelling machines to eliminate the problems associated with the traditional-manual method of cracking, but such locally fabricated melon seed shelling machines are not available in the market and test conducted on the machines show that their efficiencies are averagely not more than 30\% at one cycle [5] This is because key parameters which directly affect the machine efficiency like; rotational speed of the machine impeller, federate of egusi seeds during cracking, moisture content of the seeds and impact force of the machine on the seeds during cracking are not taken into consideration during the design and operation phases of the locally constructed machines. To resolve this problem of Egusi cracking machine some researchers have made effort in designing melon shelling machines mostly the Igbo type as follows; The design and construction of a machine based on principle of friction between a rotating disc and a stationary disc positioned to be parallel to the rotating disc [9], the construction of a melon seed shelling machine which works on the principle of bending by feeding seeds through a sets of rollers having ridges on their surfaces [10], The designe and construction of a melon shelling using the principle of extrusion [11]. The design of an impact egusi shelling machine that works on the principle of impact force from spinning disc [12]. The aim or main objective of this work therefore is to do a critical analysis and performance evaluation of the current machine model, bring out areas of limitation which could be modified to improve on its to crack igbo, contry and pumpkin egusi efficiency and reliability, and finally construct a machine of the improved version which encompasses a hopper, shelling, separation and sifting compartments, at an affordable price using local materials.

\section{MATERIALS AND METHODS}

\section{Egusi Seed Sample Collection and Preparation}

Three categories of Melon Seeds (Egusi) were used in this study. They have the following visibly peculiar characteristics:

CategoryA: Soft-Yellowish Shell (locally called Igbo Egusi);

CategoryB: Hard-Whitish Shell and Thin (locally called Contry Egusi);

CategoryC: Soft-Whitish (or brownish) Shell and Thick (locally called Pumpkin Egusi).

All the above seed categories are readily available and locally grown in Cameroon. The samples were obtained from the Bamenda Food Market North.West.Region, while some from the Buea Main Market and others from local farmers in Muyuka, South West Region Cameroon. To prepare the seeds for machine cracking, the hand picking process was employed in a bid to eliminate debris and immature seeds and washed thereafter to eliminate foreign matter (dust) from the seed surface which could possibly affect the colour of the cracking seeds and accelerate spoilage [13] The seeds were then sun dried for 6 hours to possibly take them back to their initial dry state. The different seed categories are presented below:

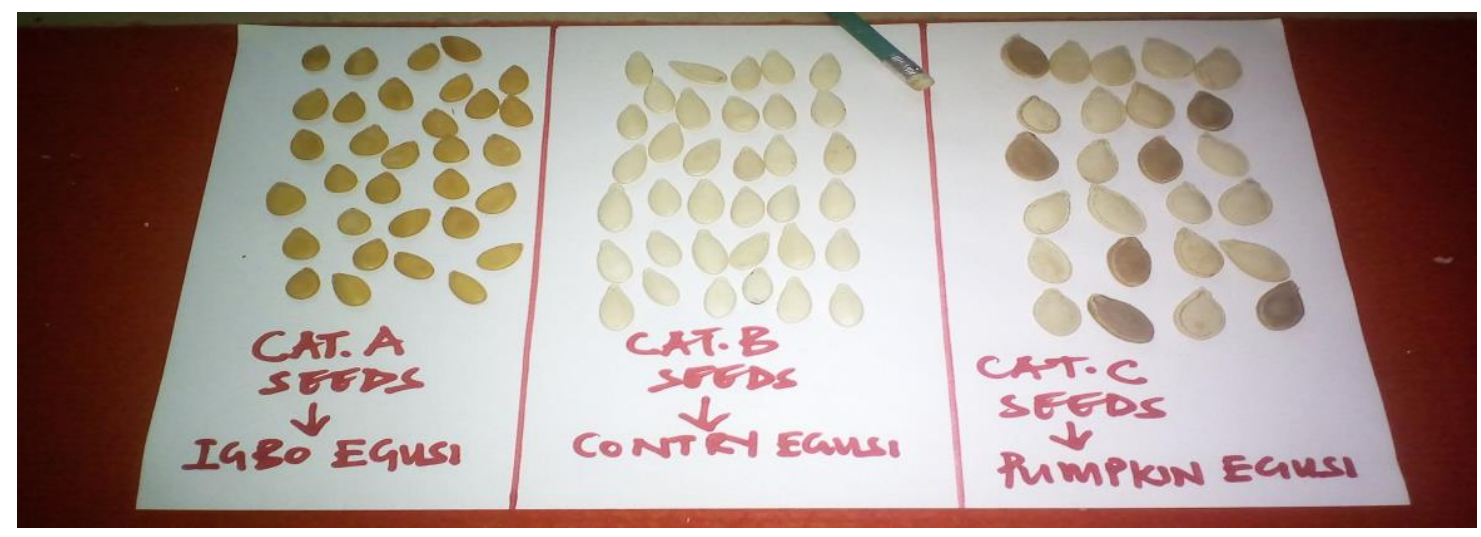

\section{Dimensioning of the Seeds}

Figure 1 Different Seed Categories

Using a venier caliper, the principal dimensions like length, width, thickness, and surface area were obtained. Thirty grains of each seed category were randomly selected and the dimensions calculated and averaged, taking into consideration. For density, for each seed category, 500 grains (with noted mass) were tied in a massless polythene bag, and immersed in a graduated beaker of water and the volume of water displaced gotten. The ratio of the mass on the volume gave the density of the 500 grains, and the average gave the density of 1 grain. This was repeated twice and the average values recorded as density for the different categories of egusi seeds. 


\section{Design Considerations}

The following key factors were considered in the design of the improved version of the egusi seed cracking machine:

- Strength: For the construction of this improved prototype, Materials of adequate strength and stability were used for fabrication (i. e. mild steel);

- Suitability: The machine was designed to have a comfortable capacity and less complexity in its operation, so that machine could be easily affordable and operated by small scale farmers;

- Local Availability: The materials used for the fabrication of the machine components were sourced locally.

- Mode of Fabrication/Machinability: Most of the machine components were fabricated using the simple process of welding. The fabrication material could easily be machined as desired.

- Categories of Available Egusi Seeds: The physical and mechanical properties of the categories of egusi seeds available also helped in shaping some of the design considerations.

\section{New Machine Design Computations}

The international design standards and equations employed are referenced from those presented by Khurmi and Gupta (2005)

[14] in their text titled A Textbook of Machine Design.

\section{- Total Machine Power Requirement}

$$
\text { Motor } P=T \omega
$$

Where P: Power (watts); T: Torque on the shaft (Nm); $\boldsymbol{\omega}$ : Angular velocity of shaft (rpm)

But

$$
\boldsymbol{T}=\boldsymbol{F} . \boldsymbol{r}=6.7 \times 9.8 \times 0.032=2.10 \mathrm{Nm}
$$

Where $\mathbf{F}$ : Total Load on shaft (N); r: Radius of the driven pulley

Also,

$$
\boldsymbol{\omega}=\frac{2 \pi N}{60}
$$

Therefore

$$
\text { Motor } P=\frac{2 \pi N T}{60}=\frac{2 \times 3.142 \times 1345 \times 2.10}{60}=295.82 \mathrm{~W}
$$

Also

$$
\text { Fan } P=I V=0.3 \times 220=66 \mathrm{~W}
$$

Therefore

Total Machine Power $=$ Motor P + Fan $P=295.82+66=361.82 \mathrm{~W}=0.48 H P$

1.5HP, Single Phase, $1345 \mathrm{rpm}$ Electric motor was chosen for the new design.

\section{- Pulley Diameters}

Considering the power to be transmitted between the electric motor and the cracking (rotor) shaft, the ratio of pulley for the electric motor to that of the cracking shaft was 1: 1.03.

Neglecting Belt Tension: $\mathbf{N 1 D 1}=\mathbf{N 2 D 2}$

Where N1: speed of driving pulley (rpm); N2: Speed of driven pulley (rpm); D1: Diameter of driving pulley (mm); D2:

Diameter of driven Pulley (mm).

Therefore $\mathrm{N} 2=1300 \mathrm{rpm} \mathrm{N1}=1345, \mathrm{D} 1=70 \mathrm{~mm}, \mathrm{D} 2=72 \mathrm{~mm}$

Considering the short distance between the driver and driven pulley, a V-grooved pulley design was chosen.

\section{- Belt Speed}

The belt speed (V) was obtained from eqn. as:

$$
\boldsymbol{V}=\frac{\boldsymbol{\pi} \boldsymbol{N 1 D 1}}{\mathbf{6 0}}=\frac{3.142 \times 1345 \times 0.07}{\mathbf{6 0}}=4.93 \mathrm{~m} / \mathrm{s}
$$

NB: Since there is no slip, the driving and driven pulleys run at $4.93 \mathrm{~ms}^{-1}$

\section{- Determination Belt Length}

The length of the belt $(L)$ was obtained using equation presented from [14] .

But Center Distance, $C$, was obtained as follows:

$$
L=2 C+\frac{\pi}{2}(D 1+D 2)-\left(\frac{D 2-D 1}{4 C}\right)
$$

$$
C=\frac{D 1+D 2}{2}+D 1=141 m m
$$

Therefore $\boldsymbol{L}=\mathbf{5 0 1 . 1 \mathrm { mm }}$

- Determination of Wrap Angles

The Wrap angle was calculated as follows:

$$
\sin \boldsymbol{\beta}=\frac{\boldsymbol{R}-\boldsymbol{r}}{\boldsymbol{C}}=\frac{36-35}{141}=4.52^{\circ}=0.0791 \mathrm{rads}
$$

Where $\boldsymbol{R}$ : Radius of driven pulley (mm); $\boldsymbol{r}$ : Radius of driver pulley (mm); $\boldsymbol{C}$ : Center distance (mm). 
- Determination of Belt Tensions

The tensions in the tight and slack sides of the belt were calculated thus:

$$
\begin{gathered}
P=(T 1-T 2) V \\
\left(\frac{T 1}{T 2}\right)=e^{f \alpha}
\end{gathered}
$$

Where $\boldsymbol{P}$ : Belt Power (W); V: Belt speed $\left(\mathrm{ms}^{-1}\right) ; \boldsymbol{T} 1$ and $\boldsymbol{T} 2$ : Tensions on the tight and slack sides of the belt respectively $(\mathrm{N})$; $f$ : Coefficient of friction between belt and pulley; $\boldsymbol{\alpha}$ : Angle of wrap for driving pulley.

Thus $\boldsymbol{T} \boldsymbol{1}$ and $\boldsymbol{T} 2=159.16 \mathrm{~N}$ and $93.38 \mathrm{~N}$ respectively.

Coefficient of Friction between mild steel and rubber belt is 0.3

- Determination of shaft Torque and Permissible angle of Twist

$$
\begin{gathered}
\boldsymbol{M}=\left(\frac{\boldsymbol{T 1}-\boldsymbol{T 2}}{\mathbf{2}}\right) \boldsymbol{D} \mathbf{2}=50.9 \times 0.072=3.66 \mathrm{Nm} \\
\boldsymbol{\theta}=\frac{\mathbf{5 8 4 M L}}{\boldsymbol{G D}^{\mathbf{4}}}=\frac{\mathbf{1 0 6 8 . 7 2}}{\mathbf{8 8 0 7 4}}=0.01^{\circ} / \mathrm{m}
\end{gathered}
$$

Where $\boldsymbol{M}$ : Torque on shaft $(\mathrm{Nm}) ; \boldsymbol{\theta}$ : Angle of twist caused by torque on the shaft $\left({ }^{\circ} / \mathrm{m}\right) ; \boldsymbol{G}$ : constant $\left(84 \times 10^{9}\right) ; \boldsymbol{D}$ : Shaft diameter $(\mathrm{mm}) ; \boldsymbol{L}:$ Shaft Length $(\mathrm{mm})$.

Maximum permissible angle of twist is $0.3^{\circ}$. Therefore the choice of a $32 \mathrm{~mm}$ shaft is good for the design and can transmit the torque without damage. Also, as a standard procedure, a $5 \mathrm{~mm}$ key way/key was chosen for the $32 \mathrm{~mm}$ shaft.

- Impact (Static) Force to break seeds

$$
F=\sqrt{E \rho} \frac{m}{M} \omega r A
$$

Where $\boldsymbol{F}$ : Impact Force $(\mathrm{N}) ; \boldsymbol{E}$ : Young's Modulus of elasticity of melon seed $\left(\mathrm{Nm}^{-2}\right) ; \boldsymbol{\rho}$ : Density of melon seed $\left(\mathrm{Kgm}^{-3}\right) ; \boldsymbol{m}$ : Egusi seed mass (kg); $\boldsymbol{M}$ : Impeller (rotor) mass (kg); $\boldsymbol{r}$ : Impeller radius (m); $\boldsymbol{A}$ : crossectional area of seeds.

$\boldsymbol{E}=4.025 \times 10^{7}, \boldsymbol{\rho}=468, \boldsymbol{m}=0.00023, \boldsymbol{M}=6.7, \boldsymbol{\omega}=\mathbf{1 3 0 0}, \boldsymbol{r}=0.105, \boldsymbol{A}=0.056$

Therefore, $F=4.66 \times 10^{7} \mathrm{~N}$

\section{Machine Performance Evaluation}

The performance of the improved machine was evaluated based on two factors; the cracking Efficiency and the Percentage of seed damaged (or Broken). This was done at a constant rotational speed of the cracking disk and constant spreading time of the seeds.

- Cracking Efficiency [15]

This gives you an idea of how reliable the machine is in terms of number of cracked seeds that exit the machine through the outlet chute.

$$
\eta e=\frac{N s u+N s b}{N t} X 100
$$

Where $\eta \boldsymbol{e}$ : Percentage seeds cracked (\%); $\boldsymbol{s} \boldsymbol{s} \boldsymbol{u}$ : Number of Seeds cracked (Unbroken); $\boldsymbol{N} \boldsymbol{s} \boldsymbol{b}$ : Number of seeds cracked (Broken); $\boldsymbol{N t}$ : Total Number of Seeds put into the machine

- Percentage of Seeds Damaged [16]

$$
\eta \boldsymbol{b}=\frac{N u b+N s b}{N t} X 100
$$

Where $\eta \boldsymbol{b}$ : Percentage of seeds damaged (\%); $\boldsymbol{N u \boldsymbol { b }}$ : Number of broken seeds (Unshelled); $\boldsymbol{N} \boldsymbol{s} \boldsymbol{b}$ : Number of Broken seeds (cracked); $\boldsymbol{N}$ : Total Number of seeds put into the machine

- $\quad$ Separation Efficiency [16]

This was used to evaluate the effectiveness and reliability of the fan (blower) system.

$$
\eta s=\frac{W 1}{W 2} X 100
$$

Where $\eta \boldsymbol{s}$ : Separation efficiency (\%); W1: Final Weight of seeds (Kg); W2: Initial Weight of Seeds

\section{RESULT AND DISCUSSION}

\section{Dimensions Optained From the Three Categories of Seeds}

The measured physical dimensions of the three seed categories of egusi seeds are presented in the table below. From observation of the details, Category C (Soft-whitish/brownish shell and thick) seeds are averagely much longer, wider, thicker, denser and obviously cover the largest surface area comparatively. And those from Category A have the least of the above mentioned dimensional quantities. 
Table 1 Dimensional Characterization of seeds

\begin{tabular}{cccccc}
\hline SN & Property & $\begin{array}{c}\text { Number of } \\
\text { Seeds }\end{array}$ & Cat.A $( \pm$ SD $)$ & Cat.B $( \pm$ SD $)$ & Cat.C $( \pm$ SD $)$ \\
\hline 1 & Length $(\mathrm{m})$ & 30 & $0.015 \pm 0.003$ & $0.018 \pm 0.007$ & $0.026 \pm 0.001$ \\
2 & Width $(\mathrm{m})$ & 30 & $0.009 \pm 0.0005$ & $0.011 \pm 0.0003$ & $0.014 \pm 0.0007$ \\
3 & Thickness $(\mathrm{m})$ & 30 & $0.001 \pm 0.0002$ & $0.002 \pm 0.0004$ & $0.003 \pm 0.0005$ \\
4 & Surface Area $\left(\mathrm{m}^{2}\right)$ & 30 & $0.037 \pm 0.002$ & $0.048 \pm 0.002$ & $0.056 \pm 0.002$ \\
5 & Density $\left(\mathrm{Kgm}^{-3}\right)$ & 1000 & $405 \pm 15.20$ & $446 \pm 18.32$ & $468 \pm 22.45$ \\
\hline
\end{tabular}

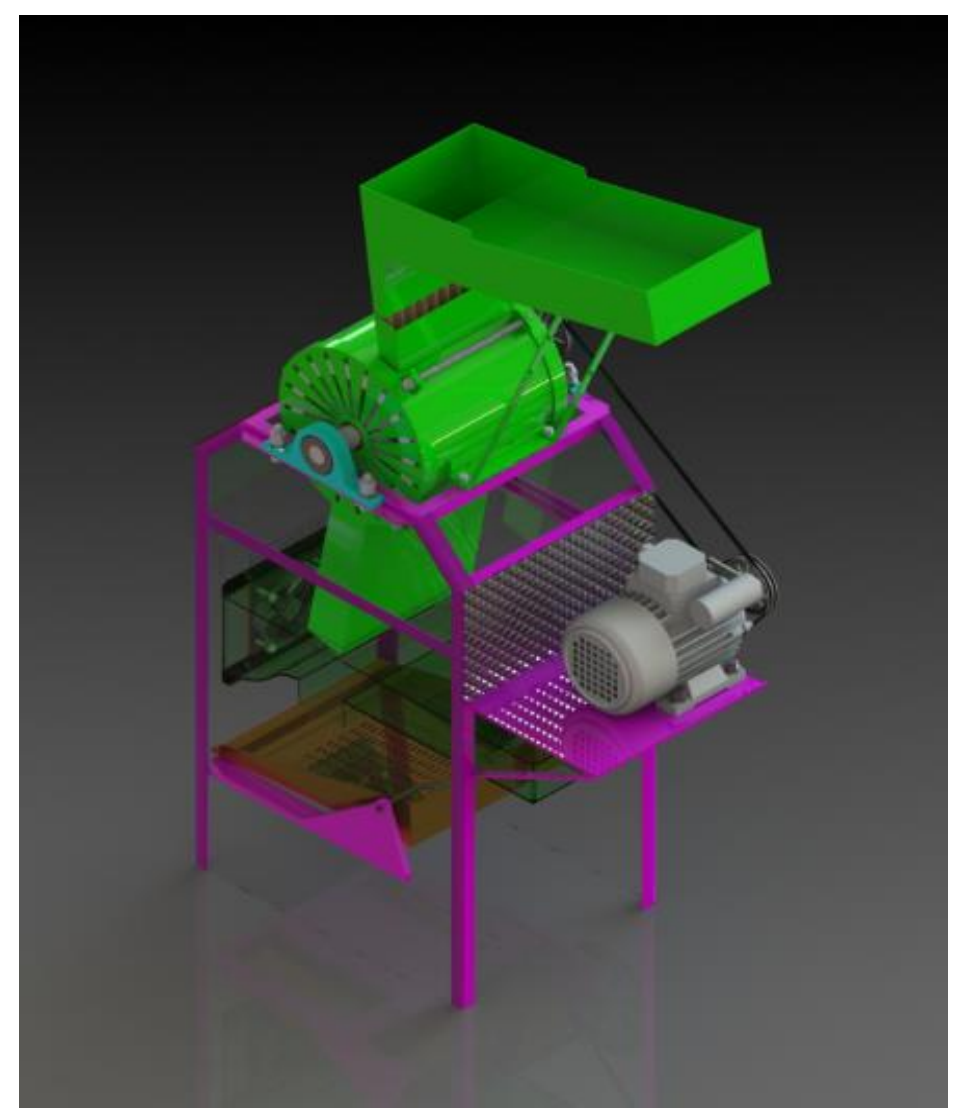

Figure 2 Machine Assembly (3D)

Nomenclature of the New Machine Design 


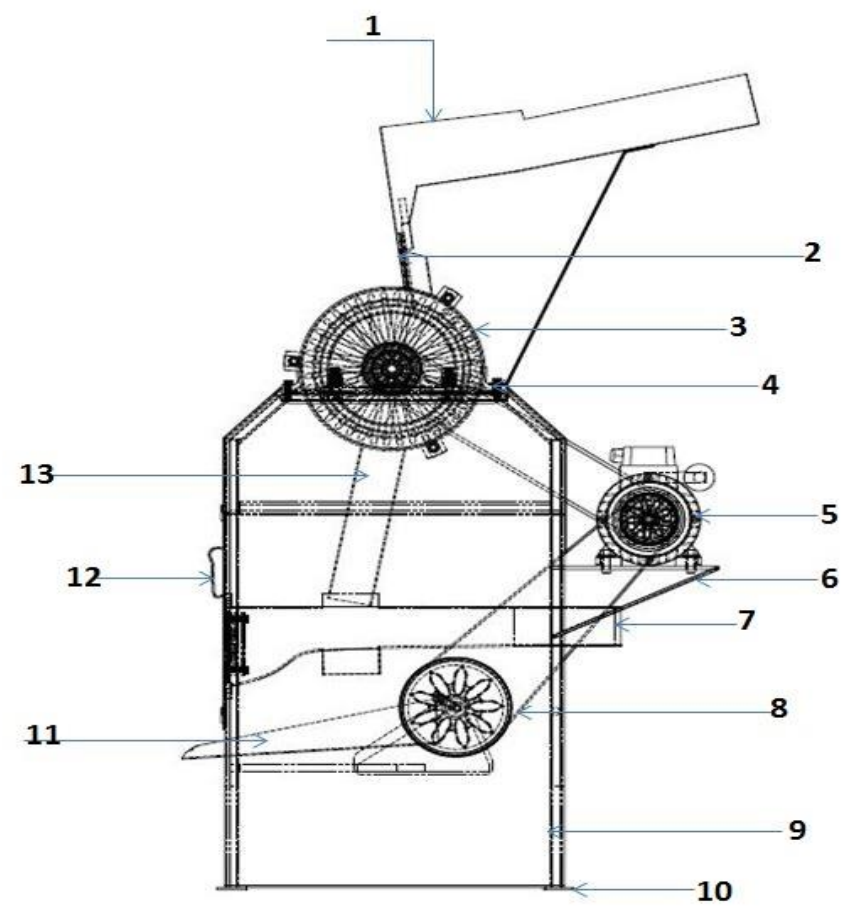

Figure 3 Side View for Nomenclature

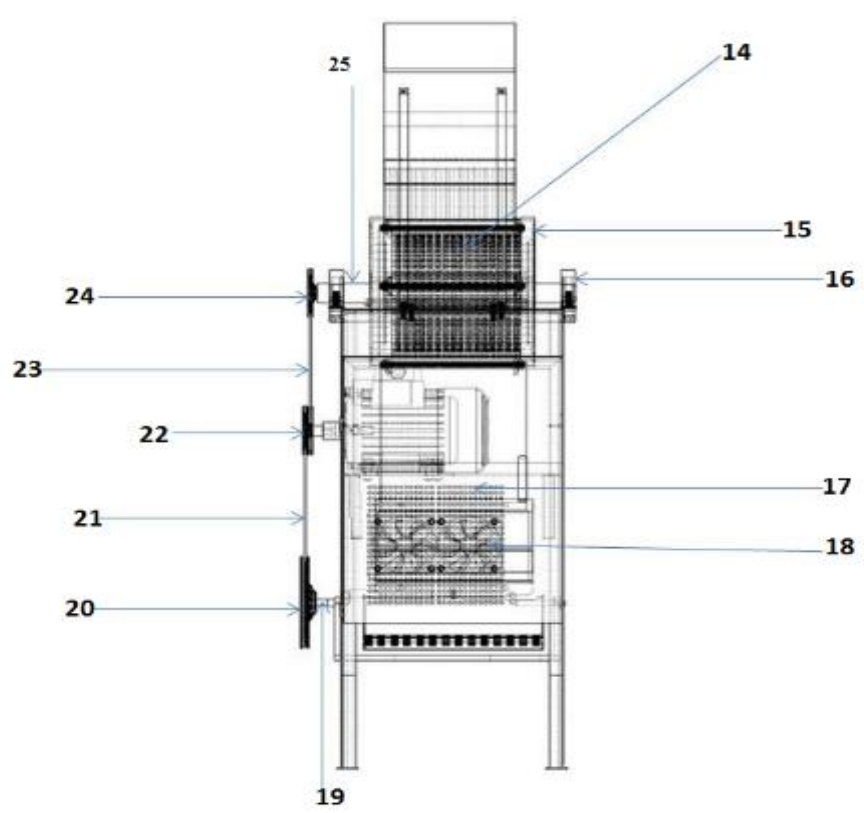

Figure 4. Front View for Nomenclature 
Table 2 Nomenclature of new machine design

\begin{tabular}{|c|c|c|c|}
\hline 25 & Rotor shaft & 1 & Bought \\
\hline 24 & Rotor Pulley & 1 & Bought \\
\hline 23 & V-Belt (to rotor) & 1 & Bought \\
\hline 22 & Motor double grooved V-Pulley & 1 & Bought \\
\hline 21 & V-belt (to sieve) & 1 & Bought \\
\hline 20 & Sieve V-Pulley & 1 & Fabricated \\
\hline 19 & Sieve shaft & 1 & Bought \\
\hline 18 & Fan (Blower) & 2 & Bought \\
\hline 17 & Metal Grid & 1 & Bought \\
\hline 16 & Journal Bearing & 2 & Bought \\
\hline 15 & Shelling Unit Cover & 2 & Fabricated \\
\hline 14 & Shelling disk (rotor) & 1 & Fabricated \\
\hline 13 & Shelling Unit outlet & 1 & Fabricated \\
\hline 12 & Machine Handle & 2 & Fabricated \\
\hline 11 & Sieve/Outlet & 1 & Fabricated \\
\hline 10 & Base Support & 4 & Fabricated \\
\hline 9 & Machine Frame & 1 & Fabricated \\
\hline 8 & V-Belts & 2 & Bought \\
\hline 7 & Fan (blower) Casing & 1 & Fabricated \\
\hline 6 & Motor frame support & 1 & Fabricated \\
\hline 5 & Motor V-Pulley & 1 & Bought \\
\hline 4 & Bolt & 4 & Bought \\
\hline 3 & Fixed Cylinder & 1 & Fabricated \\
\hline 2 & Grooved wood & 1 & Fabricated \\
\hline 1 & Hopper & 1 & Fabricated \\
\hline SN & Designation & Number & Remark \\
\hline
\end{tabular}

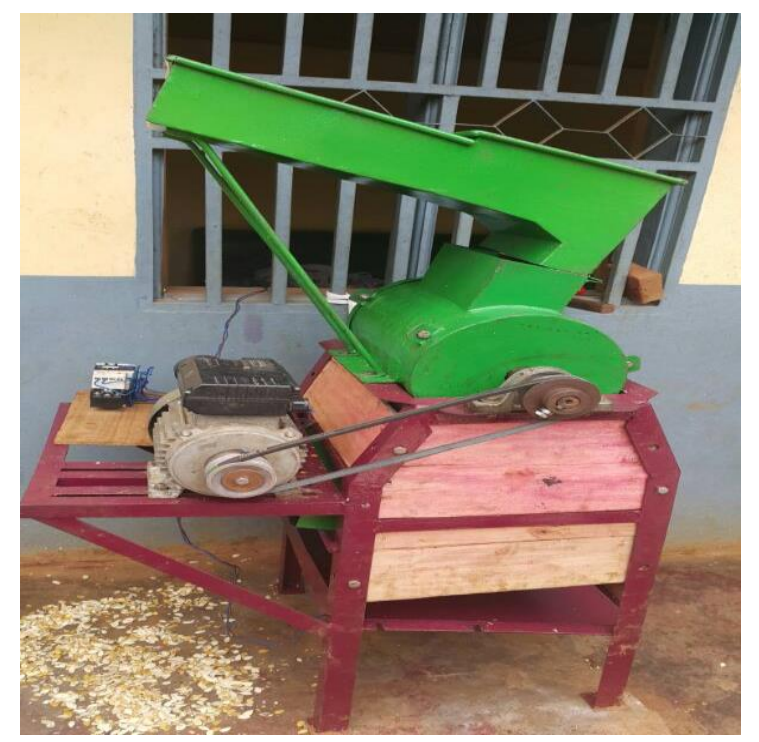

Figure 5. Realized Version 


\section{Kinematic Diagram and Functioning of the New Design}

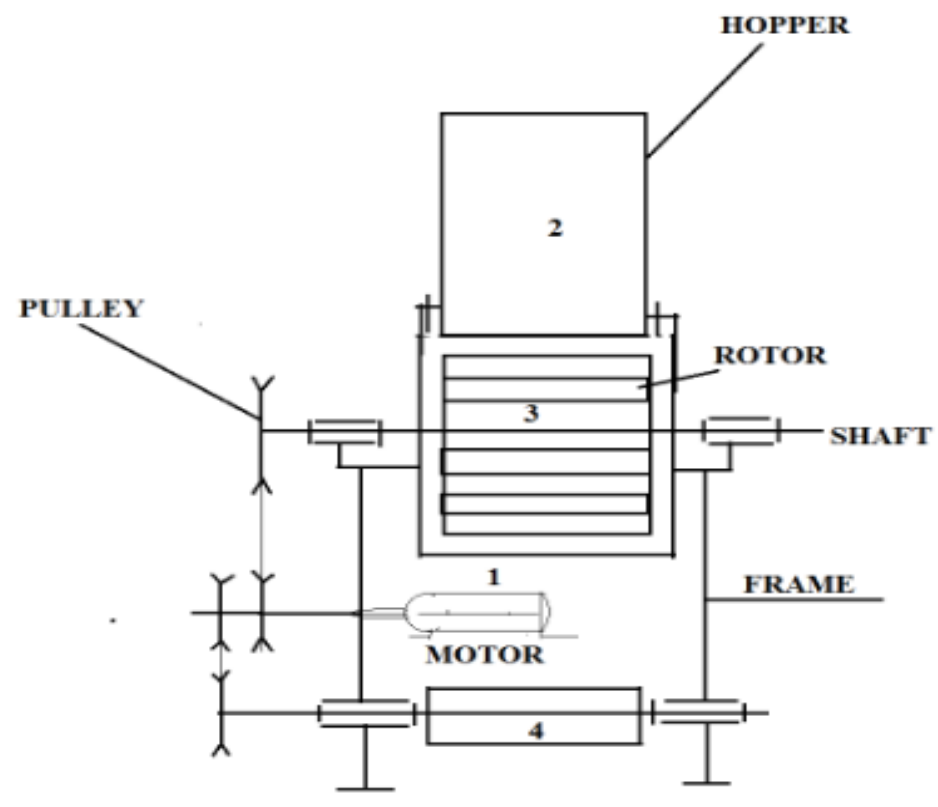

Figure 6. Kinematic diagram of New Model

When the power supply is turned on, the system is left for some time to get to steady operational state. Then seeds are introduced into the hopper (2), and the feed control flap opened to channel the seeds into the cracking unit. The rotor (3) then gives the seed an impact force which causes the removal of the shell. The seeds (plus the shells) then fall to the fan compartment by gravity, in which the lighter shells are blown off, and the heavier cotyledon drop on the sieve (4), which exits the cracked seeds from the machine to a container.

\section{Control Circuit of the New Design}

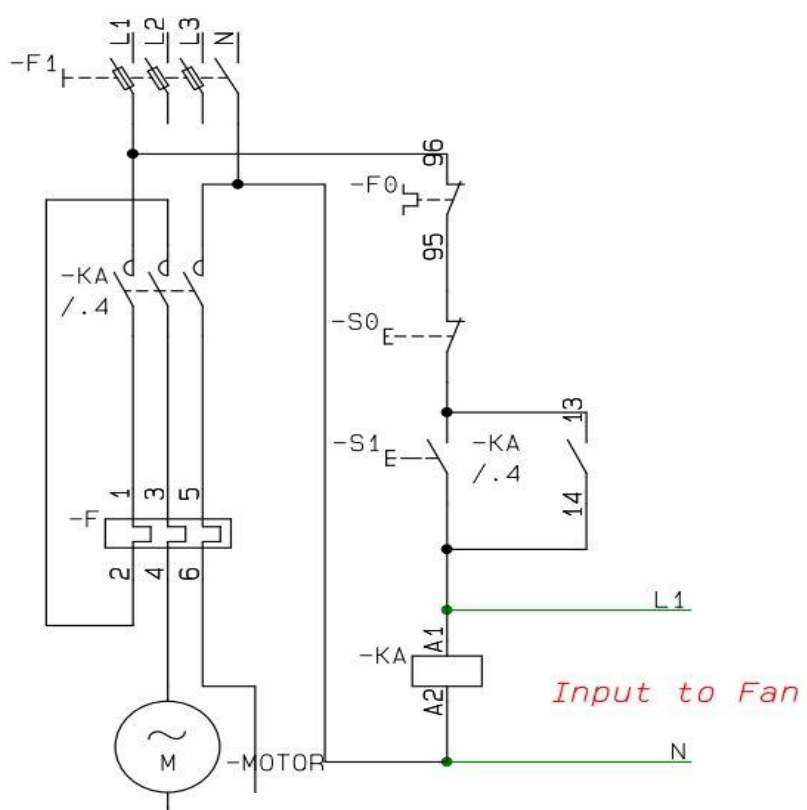

Figure 7. Control Circuit 
Table 3 Control Circuit Nomenclature

\begin{tabular}{ccc}
\hline SN & Symbol & Name \\
\hline 1 & $\mathbf{F}_{\mathbf{0}}$ & NC contact of Thermal Relay \\
2 & $\mathbf{F}_{\mathbf{1}}$ & Fuse Isolator \\
3 & $\mathbf{K}_{\mathbf{A}}$ & Contactor \\
4 & $\mathbf{A}_{\mathbf{1}} \mathbf{A}_{\mathbf{2}}$ & Coil terminal \\
5 & $\mathbf{1 3 / 1 4}$ & Hold on Contact \\
$\mathbf{6}$ & $\mathbf{F}$ & Thermal Relay \\
7 & $\mathbf{S}_{\mathbf{0}}$ & Stop Push Button \\
$\mathbf{8}$ & $\mathbf{S}_{\mathbf{1}}$ & Start Push Button \\
9 & $\mathbf{L}_{\mathbf{1}}$ & Line 1 Cable of Fuse \\
$\mathbf{1 0}$ & $\mathbf{L}_{\mathbf{2}}$ & Line 2 Cable of Fuse \\
$\mathbf{1 1}$ & $\mathbf{L}_{\mathbf{3}}$ & Line 3 Cable of Fuse \\
$\mathbf{1 2}$ & $\mathbf{N}$ & Neutral Cable \\
\hline
\end{tabular}

\section{How the Control Circuit Works}

When the fuse in $\mathrm{L}_{1}$ is connected, current flows through the $\mathbf{N C}$ of the thermal relay to the stop push button $\mathbf{S}_{\mathbf{o}}$. Applying Pressure on start push button $\mathbf{S}_{\mathbf{1}}$, current flows through and energizes the coil of the contactor $\mathbf{K}_{\mathbf{A}}$ and starts the electric motor and the fan, and the NO contacts (13/14) closes to keep the motor and fan permanently on until the stop bush button $\mathbf{S}_{\mathbf{o}}$ is used to terminate the operation. and the cycle continues.

\section{Performance Evaluation on New Model}

At a 30mins seed spreading time, tests were then carried out to evaluate the performance of the machine based on two indices; cracking efficiency and percentage of seed damaged. The above mentioned performance indices were then used as criteria for obtaining the best water-to-seed ratio during seed preparation, while taking note of the feed rate (or capacity) of the new machine model. The best or optimal performance of the machine is gotten when we register High cracking Efficiency and Low likelihood of seed damage.

Determination of Machine Capacity (Feed Rate)

Table 4 Feed rate determination on the New Machine Design

\begin{tabular}{lllll}
\hline Test & Seed Mass $(\mathrm{Kg})$ & Exit Time $(\mathrm{s})$ & Exit Time $(\mathrm{hr})$ & Feed Rate $(\mathrm{Kg} / \mathrm{hr})$ \\
\hline $\mathbf{1}$ & 0.10 & 7 & 0.0019 & 52.63 \\
$\mathbf{2}$ & 0.20 & 13 & 0.0036 & 55.55 \\
$\mathbf{3}$ & 0.25 & 16.5 & 0.0046 & 54.35 \\
$\mathbf{4}$ & 0.50 & 31.5 & 0.0087 & 57.34 \\
$\mathbf{5}$ & 0.75 & 50 & 0.0139 & 53.96 \\
$\mathbf{6}$ & 1.00 & 65 & 0.0181 & 55.65 \\
\hline
\end{tabular}

From observation of the recorded feed rate values from table 4 above, an average feed rate for the new machine design is $55.10 \mathrm{Kg} / \mathbf{h r}$. The above registered exit times are the mean values obtained for the three different seed categories for the same seed masses.

\section{Determination of Best Water-to-Seed Ratio}

Keeping the number of seeds constant during cracking, and varying the water quantity added at the level of seed preparation, the cracking efficiency and percentage of seed damage values for the different seed categories were recorded as presented by the tables below. 


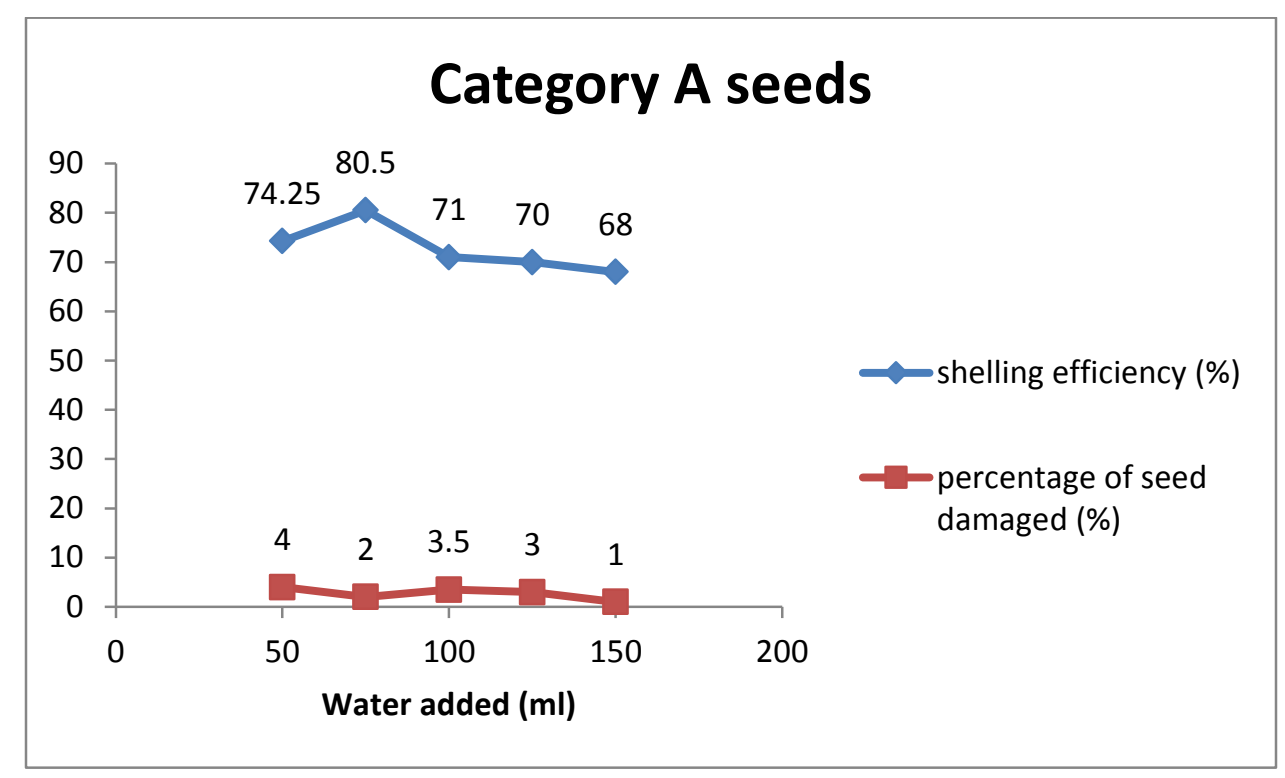

Figure 8. Water added against Machine Performance for Category A Seeds

Generally, with increase in the quantity of water added, for the same seed mass, there was an increase in the cracking efficiency (from $74.25 \%$ to $80.5 \%$ ) and a drop in the percentage of seed damaged (from $4 \%$ to $2 \%$ ). Constant addition of water therefore saw the cracking efficiency dropping rapidly to $70.5 \%$ and the percentage of seed damaged increasing to $4 \%$. Optimal performance therefore occurred at a cracking efficiency of $80.5 \%$ and at a seed breakage rate of $2 \%$, The soaking time must be brief, and the seeds air-dried for 30 mins before cracking is carried out.

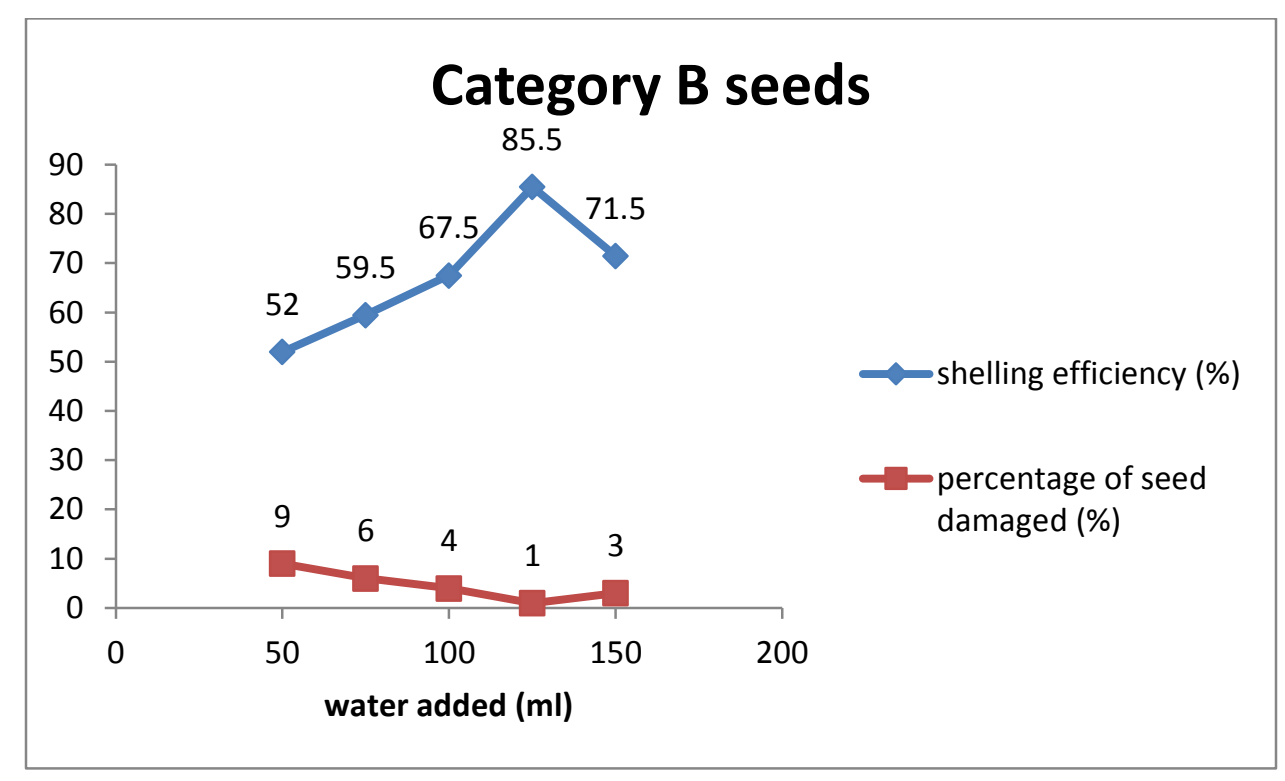

Figure 9. Water added against Shelling Performance

With a constant addition of water, there was a constant increase in the cracking efficiency (from $52 \%$ to $85.5 \%$ ) with a constant drop in the seed damage percentage (from $9 \%$ to $1 \%$ ). Beyond these values, there was a drop in cracking efficiency and an increase in the seed damage percentage. Optimal performance was therefore obtained at $85.5 \%$ cracking efficiency and $1 \%$ seed damage.. 


\section{Category $C$ seeds}

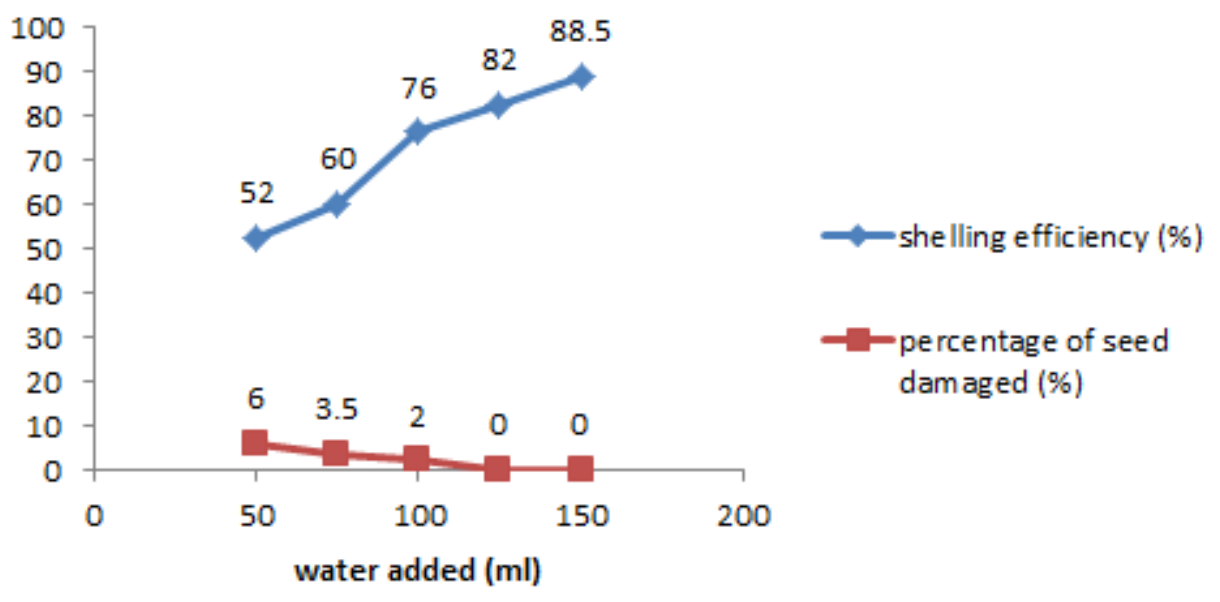

Figure 10. Water added against shelling performance

It was observed here that, the greater the quantity of water, the greater the cracking efficiency and the fewer the number of seeds broken. Instances of $0 \%$ seed damage were recorded severally as water was continuously being added. In other cases, these seeds (category C) were soaked in water for more than $20 \mathrm{mins}$, and then allowed to drain off. When cracking was done at, $100 \%$ cracking was recorded.

\section{CONCLUSION}

At the design specifications of the improved machine, outstanding cracking efficiencies of $80.5 \%, 85.5 \%$, and $89.5 \%$ were obtained for cracking seed categories A, B, and C respectively. This machine was capable of cracking three different categories of egusi with category A having a soft and thin shell, categories B having a very hard shell and category $\mathrm{C}$ with a soft and thick shell. The contry egusi and the pumpkin egusi which have no machine for cracking due to their shell nature can now be process for industrial and commercial purposes. Other interesting adaptions to the new versions are a "seed orientator" attached to the hopper, a blower, and space for a sieve. In a bid to alter the seed moisture content before cracking, the water to seed ratio standards experimentally determined will go a long way to assist machine operators. This will help reduce excessive seed damage and reduce the cost of production.

\section{ACKNOWLEDGMENTS}

I am very grateful to the personnel in the FONAB mechanical fabrication workshop and Joel agric tools at mile 4 Nkwen for helping me through the practical part of the work. I am also grateful for Mr Waindim Yisa Tufoin Albert who was providing me with documents from Nigeria.

\section{REFERENCES}

[1] Adekunle, A.S., Ohijeagbon, I.O., Olusegun, H.D. (2009). Development and Performance Evaluation of Manually and Motorized Operated Melon Shelling Machine using impact technique. Journal of Engineering Science and Technology Review, 2:12-17

[2] Ajibila O.O.; Eniyemo S.E.; Fasina O.O. and Adeko K.A (1990). Mechanical Extraction of oil from Melon Seeds. Journal of Agricultural research 45, 1.

[3] Ogbe, A.O. and George, G.A.L. 2012. Nutritional and anti-nutrient composition of melon husks: potential as feed ingredient in poultry diet. Research Journal of Chemical Sciences, 2:35-39.

[4] Nwosu, R.C. (1988). Engineering Properties of Egusi fruit and the design of Egusi seed extraction equipment. 
B.Eng. Project Report, Department of Agricultural Engineering, University of Nigeria, Nsukka.

[5] Oloko S.A. and Agbetoye. (2006). Development and Performance Evaluation of a melon seed depodding Machine. Agricultural Engineering International. CIGR Journal manuscript PM 06018. Vol. VIII

[6] Omidiji M.O.; Oyedokun J.B.; Akinlosotu T.A.; Ogunfowora A.O. and Oputa C. O. (1985). Exploratory Survey on cropping systems and Related Activities at Ilugun Local Government Area, Ogun State. In: Farming System Research in Nigeria; Diagnostic Surveys,.

[7] Olayiwola C.B.: (1987)"Women in Agriculture”, Paper Presented at the Workshop on Women in Development, Sponsored by DFRRI, Abuja, 14th -16th September. Pp 6-9,

[8] Kassim M. J; Victor U. and Isaac N. I. (2011). Development and Evaluation of a melon shelling and cleaning machine. Journal of Emerging Trends in Engineering and Applied Sciences. (JETEAS) 2(3): 383-388, Scholarlink Research Institute Journals, 2011, (ISSN: 2141-7016).

[9] Fadamoro I. :Design and Construction of a Manually Operated Melon Sheller, Unpublished B.Sc. Report, Department of Mechanical Engineering, University of Ilorin, 1999

[10] Fashina A.B.: The Design and Development of a Melon Sheller. Unpublished B.Sc Project Report, Department of Agriculture, University Of Ife, Nigeria, 1971.

[11] Obienwe D.S. :Design, Construction And Testing Of An Electrically Powered Melon Sheller, Unpublished Project Report M. Eng. Thesis. Department Mechanical Engineering University of Ilorin, Nigeria, 2002.

[12] Odigboh E.U.:“Impact Egusi Shelling Machine Transaction of the ASAE, 22(5):1264-1269, 1979.

[13] Egbe D. E; Mayah T. F; Ebot E. G; Egbe P. A and Abraham J. P (2015) Performance Evaluation and Improvement on a Melon Seed Shelling Machine; World Journal of Agricultural Sciences \& Engineering; Vol 1; 1

[14] Khurmi R.S and Gupta J.K (2005). A Textbook of Machine Design (S.I. Units). Eurasia Publishing House (PVT.) Ltd. Ram Nagar, New Delhi - 110 055. Pp 1-3, 511, 727-730.

[15] Shittu, S.K., Ndrika, V.I.O. (2012). Development and performance tests of a melon (Egusi) seed shelling machine. Department of agricultural Engineering, Faculty of Engineering, Bayero University Kano, Nigeria.

[16] Ikechukwu C. U.; Olawale J. O.; Ibukun B. I.; (2014). Design and Fabrication of a groundnut shelling and separation machine. International Journal of Engineering Science Invention. Volume3, pp. 60-66. 